\title{
Limitations of CLL-1 (CLEC12A) as a putative marker of leukemic stem cells in acute myeloid leukmia
}

\author{
Shruti Daga1,2, Angelika Rosengerger1,2, Nina Krisper1,2, Albert Wölfler1,2 \\ ${ }^{1}$ Division of Hematology, Department of Internal Medicine, Medical University of Graz, Graz, Austria; \\ ${ }^{2} \mathrm{CBmed}$ - Center for Biomarker Research in Medicine, Stiftingtalstrasse 5, 8010 Graz, Austria
}

\begin{abstract}
BACKGROUND
Acute myeloid leukemia (AML) is the most common form of acute leukemia in adults $^{1}$. With help of chemotherapeutic drugs and stem cell transplantation, it is possible to achieve complete remission (CR). However, the majority will relapse within 2 years despite consolidation therapy including allogeneic stem cell transplantation. ${ }^{1}$ Despite some improvement in survival for younger AML patients over the last few decades, long-term survival is still a big challenge.

The role of leukemia stem cells (LSCs) has been implied in leukemia initiation, progression, drugs resistance and relapse of the disease following remission ${ }^{2,3}$ A number of cell surface markers to identify LSCs have been explored in the last few years ${ }^{4}$. Recently, human C-type lectin-like molecule-1 (CLL1 or CLEC12A), a myeloid lineage restricted cell surface marker has been shown to be overexpressed on blasts and LSCs making it an ideal target for development of new targeted therapies such as CAR-T-cells ${ }^{5,6}$. However, there is still controversy about its role as LSC marker and its potential as target molecule.

\section{AIMS}

- To determine CLL1 expression on leukemic subpopulations defined by different CD34 and CD38 expression levels

- To determine whether CLL1 ${ }^{\text {hi }}$ cells display high expression levels of genes associated with LSC activity

- To examine whether the expression levels of CLL1 at diagnosis may identify patients with adverse outcome
\end{abstract}

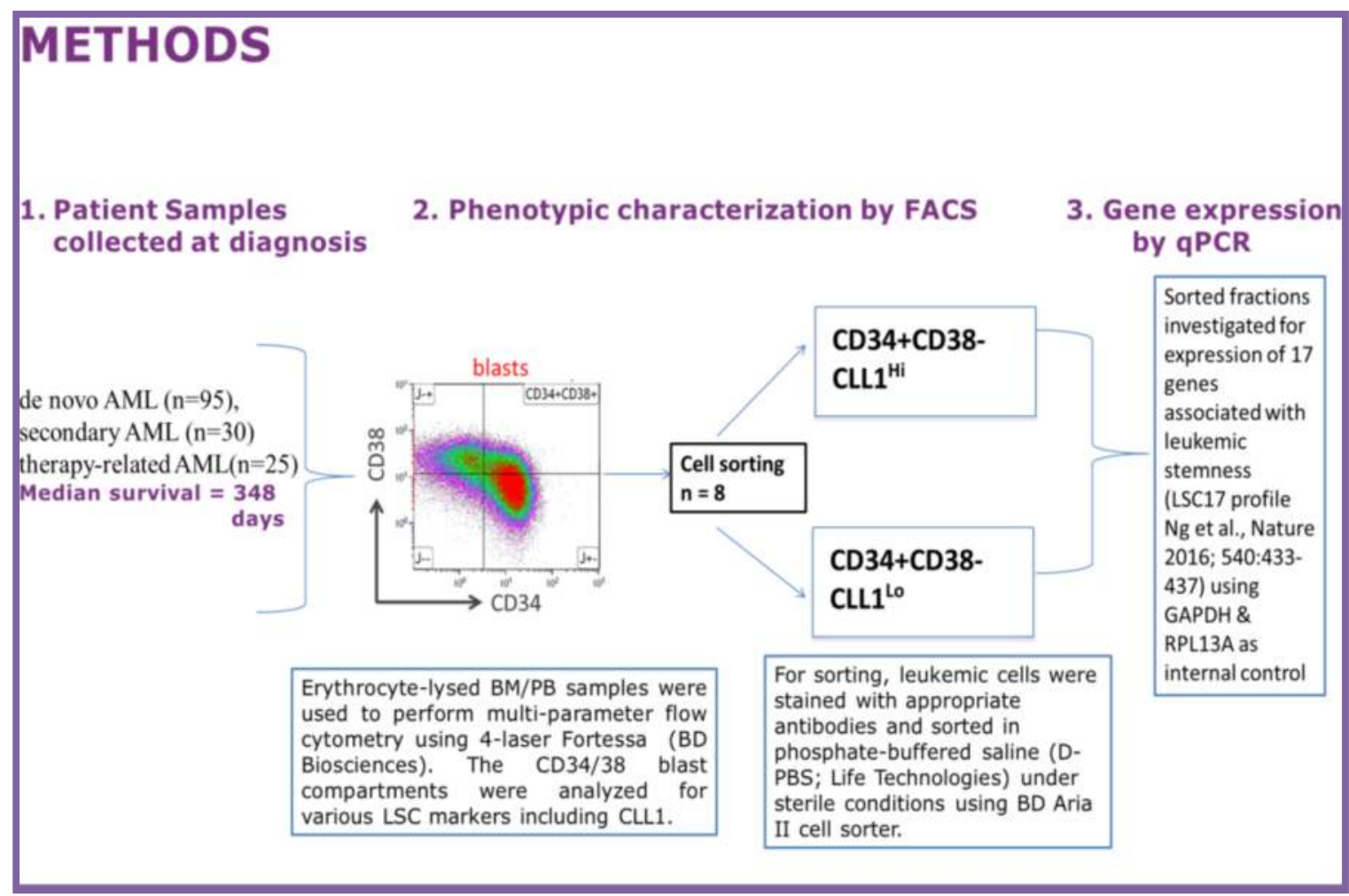

\section{REFERENCES}

Appelbaum FR, Gundacker H, et al: Age and acute myeloid leukemia. Blood 2006 107:3481- 3485.

Bonnet D, Dick JE. Human acute myeloid leukemia is organized as a hierarchy that originates from a primitive hematopoietic cell. Nat Med 1997; 3: 730-737.

. Passegue, E. et al. (2003) Normal and leukemic hematopoiesis: are leukemias a stem cell disorder or a reacquisition of stem cell characteristics? Proc. Natl. Acad. Sci. U. S. A. 100, 11842-11849

4. Saito Y, Kitamura H, et al. Identification of therapeutic targets for quiescent, chemotherapyresistant human leukemia stem cells. Sci Transl Med. 2010;2(17):17ra9.

Van Rhenen, A.; van Dongen, et al. The novel aml stem cell associated antigen CLL-1 aids in discrimination between normal and leukemic stem cells. Blood 2007, 110, 2659-2666. Saygin C, Carraway HE. Emerging therapies for acute myeloid leukemia. J Hematol Oncol. 2017;10(1):93
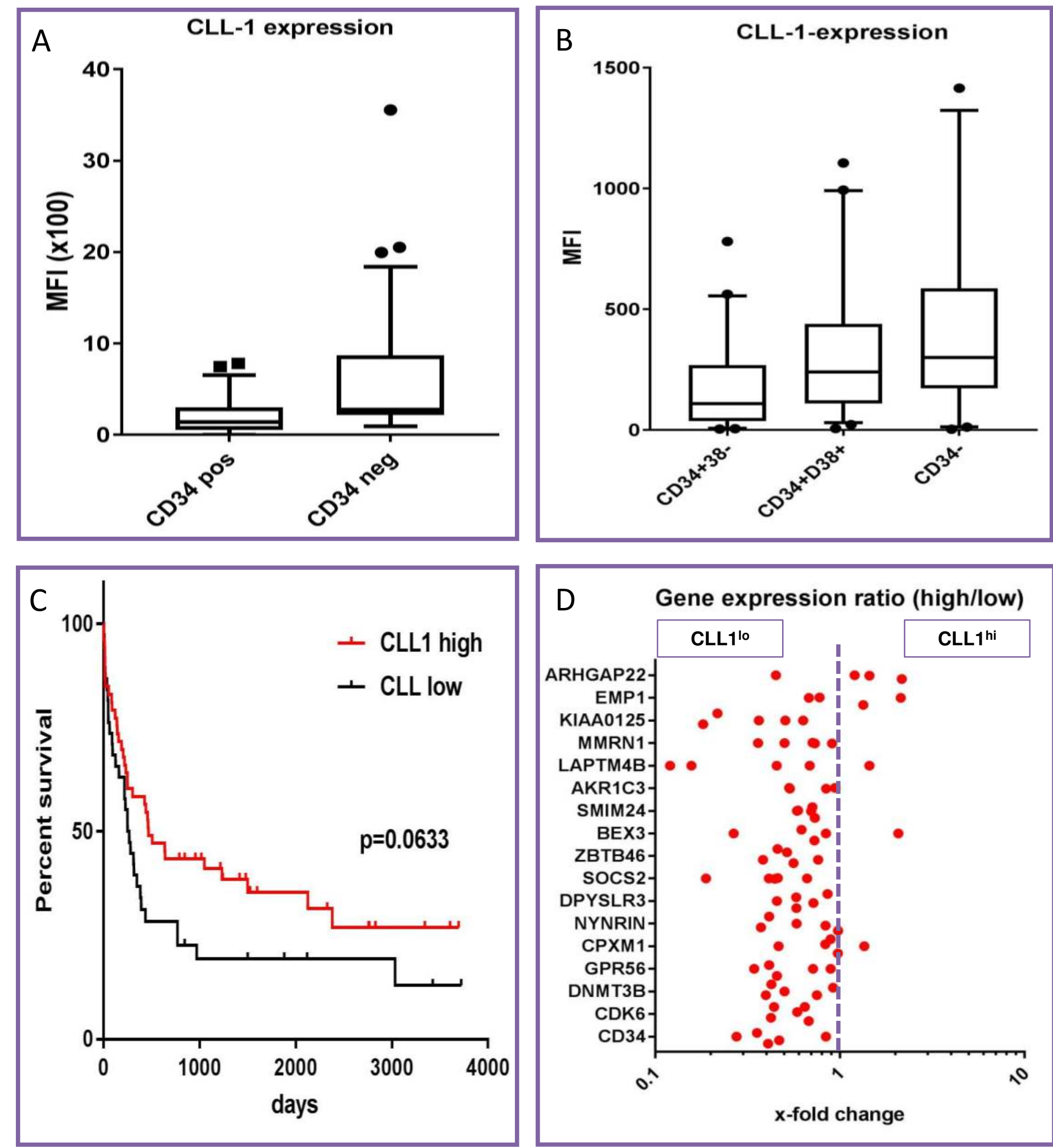

Figure 1: (A) Surface expression levels of CLL1 in CD34+ vs CD34- AMLs ( $\mathrm{p}<0.01)$. (B) Surface expression levels of CLL1 in different cellular compartments of CD34+ AML specimens ( $p<0.001$ for trend). (C) Probability of overall survival in AML patients according to the surface expression of CLL1. Patients with high CLL1 expression have a trend towards better survival. (D) Gene expression ratio of sorted $\mathrm{CD} 34^{+} \mathrm{CD} 38^{-/ \mathrm{dim}} \mathrm{CLL} 1^{\mathrm{hi}}$ vs. $\mathrm{CD} 34^{+} \mathrm{CD} 38^{-/ \mathrm{dim}} \mathrm{CLL} 1^{\text {lo }}$ cells of LSC17 genes (an $\mathrm{x}$-fold change $>1$ indicates higher expression in CLL1 ${ }^{\text {hi }}$ cells).

\section{RESULTS}

- CLL-1 expression was higher in CD34- AML ( $\mathrm{n}=42$ ) as compared to CD34+ AMLs ( $\mathrm{n}=108$ ) (Fig 1a). Within the CD34-positive AMLs, CLL-1 was significantly up-regulated in the more mature CD34 $38^{+}$and CD34- leukemic cell compartment (Fig 1b).

- Gene expression analysis revealed that most of LSC associated genes were differentially expressed between $\mathrm{CD} 34^{+} \mathrm{CD} 38^{-/ d i m} \mathrm{CLL} 1{ }^{\text {hi }}$ and $\mathrm{CD} 34^{+} \mathrm{CD} 38^{-/ \mathrm{dim}} \mathrm{CLL} 1^{\text {lo }}$ cells. Most of LSC17 genes seem to be higher expressed in the $\mathrm{CD} 34^{+} \mathrm{CD} 38^{-/ \mathrm{dim}} \mathrm{CLL1} 1^{\text {lo }}$ cells (Fig 1d).

- In 102 AML patients receiving intensive chemotherapy, patients with high CLL1 expression had a trend towards higher overall survival as compared to patients with low surface expression (Fig. 1c).

\section{CONCLUSIONS}

Among CD34-positive AML samples, CLL-1 expression was lowest in the LSC-containing CD34+38- compartment and its surface levels inversely correlated with LSC-associated gene expression. Furthermore, CLL-1 expression did not impact on outcome in AML patients receiving intensive therapy. Thus, our data indicate that CLL-1 has limited potential as LSC marker in AML.

supported by: 